Vesna M. Petrović

UDK 371.3::811.111

Univerzitet u Beogradu

Filološki fakultet - doktorske studije, modul: Kultura

Beograd

Visoka škola tehničkih strukovnih studija

Čačak

vesna.petrovic@vstss.com

\title{
USVAJANJE NOVIH REČI ENGLESKOG JEZIKA KAO STRANOG I POBOLJŠANJE GOVORNE KOMPETENCIJE U VEZI SA ODREĐENOM TEMOM PRIMENOM „PRISTUPA UČENJU KROZ KOMUNIKATIVNE ZADATKE"“
}

\begin{abstract}
APSTRAKT
U ovom radu se ocenjuju ishodi učenja novih reči kroz upotrebu komunikativnih jezičkih zadataka kod studenata koji engleski jezik uče kao strani. U proces učenja uvedena je diskusija kao tip komunikativnog zadatka da bi se omogućila upotreba jezika u smisaonom i prirodnom okruženju. Usmeni i pismeni delovi ciklusa zadatka u vezi sa zadatom temom diskusije urađeni su u obliku intervjua u parovima na nivou grupe, a njihovi odgovori su analizirani kroz dijagnostičke liste. Tačnost u izgovoru i pisanju novih reči i izraza su, takođe, uzeti u obzir u okviru analize. Ovi rezultati su predmet analize sadržaja koja je tipična za kvantitativna istraživanja. U radu je prikazana i kvalitativna analiza da bi se procenila motivacija i spremnost učenika da učestvuju u izradi komunikativnih zadataka.
\end{abstract}

Ključne reči: učenje kroz komunikativne jezičke zadatke (TBL), komunikativni pristup, zadatak, diskusija, nove reči, ocenjivanje govorne kompetencije.

\footnotetext{
APPLYING THE TASK-BASED LEARNING (TBL) APPROACH TO ACQUIRING NEW VOCABUALRY OF ENGLISH AS A FOREIGN
} 


\title{
LANGUAGE AND IMPROVING SPEAKING COMPETENCE WITH REGARD TO THE SPECIFIED TOPIC
}

\begin{abstract}
This paper evaluates the outcomes of the Task-based Learning (TBL) approach in acquiring and using new vocabulary of English as a foreign language. The discussion as the type of comunicative task has been introduced into the learning process in order to enable students to use language in a meaningful and natural environment. Oral and written parts of the oral tasks related to the topic of the discussion are formed as interviews for pairs of students in the group. Their responses were analyzed through the diagnostic list. The accuracy in pronunciation and writing of new words and phrases are also taken into account in the context of the analysis. These results were subjected to the content analysis that is typical of the quantitative research.. This paper presents the qualitative analysis as well, in order to assess the motivation and willingness of students to participate in the development of communicative tasks.
\end{abstract}

Key words: task-based learning teaching (TBL), communicative approach, task, discussion, new vocabulary, assessing speaking.

\section{UVOD}

Većina metoda i pristupa za podučavanje stranih jezika zasniva se na psihološkim teorijama o učenju i na odgovarajućim lingvističkim teorijama o načinu učenja stranih jezika. Hronološki gledano, različite teorije o učenju stranih jezika bile su popularne $\mathrm{u}$ različitim periodima u toku prošlog $\mathrm{i}$ ovog veka. Kao primer bi se mogao navesti ,,biheviorizam“ koji je kao teorija o učenju bio popularan tokom četrdesetih i pedesetih godina 20. veka. Odgovarajući metod za učenje stranih jezika bio je ,,audio-lingvalni“ metod koji je teorijski počivao na bihevioralnoj psihologiji (Lightbown and Spada 2006: 38).

Tokom šezdesetih godina 20. veka mnogobrojni lingvisti i ostali proučavaoci jezika u praksi bili su nezadovoljni preovlađujućim metodama jer je prevelika pažnja poklanjana savlađivanju jezičkih struktura. Jezička kompetencija ocenjivala se prema sposobnosti učenika da precizno upotrebljavaju gramatičke oblike (Ur 1996: 25). U prilog ovome Larsen-Friman (2000: x) navodi da je većina dotadašnjih metoda kao što su npr. „direktni metod“, „učenje jezika u zajednici“ i „komprihensivni pristup“, uglavnom osposobljavala učenike da 
koriste jezik tačno u kontekstu učionice, ali je problem nastajao kada je trebalo komunicirati u realnom kontekstu.

Nasuprot navedenim metodama, sedamdesetih godina 20. veka nastaje „komunikativni pristup”. On je za cilj imao da osposobi učenike da komuniciraju na stranom jeziku u učionici i van nje, ali je znanje jezičkih formi zanemarivano. Ispostavilo se, međutim, da ni ovakav pristup nije bio kompletan, jer je za uspostavljanje komunikacije potrebno i poznavanje odgovarajućih jezičkih struktura (Ur 1996: 19). „Pristup zasnovan na izradi komunikativnih zadataka” (Task Based Learning-TBL) usledio je kao upotpunjena verzija „komunikativnog pristupa" jer je usredsređenost na formu naznačena kao veoma bitan elemenat za uspešno komuniciranje na stranom jeziku (Willis 1996: 15).

Ovaj rad nastao je sa ciljem da se ispitaju perspektive učenja na osnovu „pristupa zasnovanog na komunikativnim zadacima” (TBL)1. Rad se bavi sledećim istraživačkim pitanjima:

- Da li će studenti koji su učestvovali u diskusiji na određenu temu, kao delu komunikativnog zadatka, biti osposobljeni da koriste nove reči u skladu sa odgovarajućim kontekstom?

- Da li će studenti koristiti novi vokabular preciznije u pogledu izgovora i pisanja ukoliko imaju veći broj prilika da upotrebljavaju nove reči u smisaonom i prirodnom kontekstu?

- Da li će studenti biti motivisani i voljni da učestvuju u izradi komunikativnih vežbi u okviru zadatka?

U prvom delu rada dat je prikaz literature i relevantnih istraživanja koja se nalaze u osnovi TBL pristupa. Glavni deo rada bavi se teorijskim opisom ciklusa zadatka koji čini okosnicu pomenutog pristupa, kao i prezentacijom konkretnog primera primene TBL pristupa na određenom segmentu nastavnog plana iz predmeta Engleski jezik 2 u Visokoj školi tehničkih strukovnih studija (VŠTSS) ${ }^{2}$ u Čačku sa studentima prve godine studija. Nakon toga, sledi kvantitativna analiza dobijenih podataka, kao i kvalitativna analiza u vidu zapažanja nastavnika. U zaključku je dat komentar o proceni ispunjenosti cilja sprovedenog istraživanja, kao i implikacije za buduća istraživanja u ovoj oblasti.

1 Dalje u radu biće korišćen akronim TBL (Task-based learning) koji označava „pristup zasnovan na izradi komunikativnih zadataka“.

2 Dalje u radu biće korišćen akronim VŠTSS koji označava Visoku školu tehničkih strukovnih studija. 


\section{PREGLED LITERATURE I RELEVANTNIH ISTRAŽIVANJA}

U ovom delu rada biće objašnjena različita viđenja autora koja govore o dobrim i lošim stranama ,pristupa zasnovanog na izradi komunikativnih zadataka (TBL)“.

U radu Alija Šehadea (Shehadeh u Edwards and Willis 2005: 13-15) $\mathrm{u}$ uvodnom razmatranju postavljeno je pitanje da li podučavanje obavezno dovodi do učenja, tj. da li su podučavanje i učenje izjednačeni sa pretvaranjem ulazne informacije $u$ izlaznu informaciju. Razlog za uvođenje TBL pristupa $u$ podučavanje jezika, kako navodi autor, je činjenica da učenici iz škola izlaze sa odličnim znanjem gramatike, ali da je nivo komunikativne kompetencije u ciljnom jeziku nezadovoljavajući. Istraživanja vezana za usvajanje drugog jezika pokazala su da su strategije učenja i kognitivni procesi u velikoj meri nezavisni od načina podučavanja. Zbog toga je bilo potrebno uvesti novi pristup učenja i podučavanja koji bi obezbedio kontekst za aktiviranje procesa usvajanja drugog jezika. Oslanjajući se na teorije vezane za učenje jezika došlo se do zaključaka da on treba da počiva na procesu usvajanja, kao i na smisaonim aktivnostima i zadacima koji naglašavaju komunikaciju i značenje, a ne samo na krajnjem ishodu. Ono što ovaj pristup čini kompletnijim jeste da pored toga što je težište na komunikaciji, značenju i tečnom govoru, značaj se takođe pridaje i svesnom učenju jezičke forme i gramatike, jer se smatra da je za efikasno učenje jezika i sposobnost komunikacije veoma značajno učenje lingvističkih formi i struktura. Autor dalje iznosi definicije i kriterijume koji karakterišu zadatak kao centralnu komponentu TBL pristupa. Na osnovu prethodnog iznosi definiciju da je zadatak:

,aktivnost koja ima nejezičku svrhu ili cilj sa jasnim ishodom, pri čemu se koriste sve četiri jezičke veštine ili neka od njih da bi se prenelo značenje na način na koji se jezik upotrebljava u realnom životu“" (Shehadeh u Edwards and Willis 2005: 18, 19) $)^{3}$.

$\mathrm{Na}$ osnovu istraživanja jezika učionice, autor takođe iznosi teorijska objašnjenja o osobinama zadataka, vrstama zadataka i uslovima u kojima se oni primenjuju.

Dalje u okviru ovog poglavlja objašnjeni su različiti teorijski pristupi, istraživanja i hipoteze koji predstavljaju podrobnije obrazloženje TBL pristupa i razloga za njegovu primenu u nastavi stranih jezika.

Saglasno sa prethodno pomenutim razmatranjem „hipoteza interakcije“ predviđa da je za razvoj jezika neophodna razumljiva ulazna informacija i

3 Sve citate prevela je autorka ovog rada budući da su dostupni samo u originalu na engleskom jeziku. 
mogućnost da se proizvede modifikovana izlazna informacija. Istraživanja $u$ okviru ove hipoteze imala su za cilj da pokažu kako razne vrste zadataka, njihove osobine i dimenzije utiču na shvatanje značenja, modifikaciju međujezika i izlaznu informaciju. Rezultati su potvrdili da shvatanje značenja jezika aktivira procese za njegovo usvajanje (Ellis, Tanaka and Yamazaki 1994. u Edwards and Willis 2005: 21).

„Hipoteza produkovanog jezika“, tj. jezika koji učenik produkuje (Krashen 1985, Swain 1998, 2000. u Edwards and Willis 2005: 21, 22) nije samo znak stečenog znanja, već i rezultat učenja jezika. Svejn (Swain) naglašava da produkovani jezik podstiče učenike da idu korak dalje od semantičke analize ciljnog jezika ka sintaksičkoj analizi i ka svesnom razmišljanju o jeziku koji se produkuje. U tom smislu, prilikom komunikacije, učenici primećuju da postoji neusaglašenost između onoga što umeju da kažu i onoga što bi želeli da kažu, što ih navodi da svoj lični međujezik na neki način prošire i premoste prazninu koja postoji u znanju. Istraživanja u okviru ove hipoteze bila su usmerena na ispitivanja kako različiti tipovi zadataka i njihovi različiti aspekti mogu uticati na shvatanje značenja i forme za produkovanje modifikovanog ili razumljivog jezika.

Pobornik „kognitivne perspektive“ (Skehan 1998 u Edwards and Willis 2005: 23, 24) razlikuje tri aspekta jezičke kompetencije: tečnost u govoru, tačnost i složenost upotrebe jezičkih struktura ciljnog jezika. Na osnovu ovoga mogu se upotrebljavati zadaci koji smišljeno podstiču onaj aspekt koji želimo da učenik savlada. Ono što je neophodno znati, a čime se jezička istraživanja bave, jeste koji tip zadataka podstiče razvoj određenog aspekta. Na osnovu „kognitivnog“ pristupa, Skehan (Skehan) ističe principe koji čine model za instrukciju zadatka. Potrebno je najpre izabrati raznovrsne jezičke strukture ciljnog jezika; zatim birati zadatke tako da se postigne izbalansiran razvoj jezika do postizanja cilja; i na kraju, povećati broj prilika za svesnu usredsređenost na formu i stvoriti ciklus odgovornosti, tj. uvesti učenike u proces evaluacije.

„Društveno-kulturna perspektiva“ se bazira na proučavanjima Vigotskog (1987. u Edwards and Willis 2005: 24, 25) koji tvrdi da socijalne aktivnosti u kojima govornik učestvuje predstavljaju glavni izvor kognitivnog procesa. Shodno tome, navedeni pristup bavi se proučavanjem načina na koji se zadaci ispunjavaju kroz zajedničke aktivnosti, kao i načina na koji zajednička izrada samih zadataka utiče na proces učenja stranog jezika. U prilog ovome govore i istraživanja koja navodi Svejn (Swain 1997 u Edwards and Willis 2005: 24, 25), pokazujući da su u zajedničkim dijalozima učenici uspeli da premoste određeni zadatak na određenom jezičkom nivou koji niko od njih pojedinačno nije uspeo 
da izvede. Ujedno, autorka je pokazala da se rešenje koje su učenici pronašli za određeni zadatak zadržalo u njihovom sistemu međujezika.

Socijalna interakcija omogućava ovakvo učenje koje se objašnjava kao proces ,građenja“ (eng. scaffolding), gde učenici prvo uspeju da upotrebe novu jezičku funkciju uz pomoć ostalih učenika, a zatim je upotrebe i samostalno. Socio-kulturna perspektiva istražuje na koji način govornici pristupaju izvođenju određenog zadatka pre nego suštinske karakteristike samih zadaka, jer različiti učenici različito ispunjavaju isti zadatak. $\mathrm{S}$ toga je učenicima prepušteno da sami izaberu svoje strategije u učenju i način na koji će da sarađuju prilikom izrade zadataka (Ellis 2000: 209 u Edwards and Willis 2005: 25).

U skladu sa prethodnim, Vilis (Willis 1996: 11) smatra da u pristupu podučavanju stranog jezika treba obezbediti tri neophodna uslova koji moraju biti ispunjeni da bi učenici naučili jezik, a to su: izloženost realnom usmenom i pisanom jeziku koji se koristi, upotreba takvog jezika i motivacija. Postoji i četvrti uslov koji je poželjan ali nije presudan, a to je jezička instrukcija, odnosno usredsređenost na formu. Tornberi (Thornbury 1999: 96) se slaže da je učenicima potrebno skrenuti pažnju na formu, tj. ,ispravno korišćenje” da bi se postigla ispravnost u komunikaciji. Edvards i Vilis (Edwards i Willis 2005: 26) impliciraju da TBL ispunjava sva četiri navedena uslova koja su potrebna za učenje stranih jezika. TBL pristup obuhvata tri glavne faze prilikom podučavanja: ,predzadatak, ciklus zadataka (zadatak, planiranje i izveštaj) i usredsređenost na jezik (analiza i vežba)". Vilis (Willis 1996: 11) dalje iznosi da su učenici izloženi spontanoj upotrebi jezika u toku izrade sve tri faze strukture zadatka. Upotreba jezika za prirodnu komunikaciju podstiče motivaciju. U toku faze usredsređenosti na jezik, učenici imaju priliku da obrate posebnu pažnju na jezičke forme i strukture, čime se poboljšava njihova preciznost izražavanja. Tornberi (Thornbury 1999: 96) se slaže da TBL pristup podržava prirodan proces usvajanja jezika, gde tačnost prilikom upotrebe jezika proizilazi iz njegove tečne upotrebe. Osnovni cilj procesa učenja jeste da se obezbede situacije u kojima bi učenici upotrebljavali jezik koji znaju da prenesu svoje ideje, razmišljanja ili da razumeju ono što čuju. Časovi vođeni na osnovu TBL pristupa predstavljaju veliki podsticaj za učenike jer povećavaju motivaciju i zainteresovanost. Različite osobe će verovatno primetiti različite karakteristike jezika, jer njegova upotreba nije ograničena.

Međutim, i pored pomenutih pozitivnih strana TBL pristupa podučavanju stranih jezika, istraživanja u realnim uslovima učionice pokazuju da je i dalje u nastavi najzastupljeniji pristup „obrade, vežbanja i utvrđivanja” (Presentation, 
Practice Production-PPP $)^{4}$. PPP pristup učenju stranih jezika zasnovan je na bihevioralnim teorijama o učenju čiji su glavni principi ponavljanje i vežbanje. Nastavnici prezentuju oblike ciljnog jezika, zatim učenici ponavljaju te oblike i vežbaju koristeći drilovanje, odgovarajuća pitanja i odgovore da bi na kraju koristili one oblike koje su prethodno naučili. Faza utvrđivanja može obuhvatiti upotrebu ,proizvoljnih” jezičkih oblika, tako da je izloženost spontanom jeziku ovom prilikom najizraženija (Willis 1996: 135).

Uprkos tome što zagovaraju primenu TBL pristupa, autori Edvards i Vilis (Edwards i Willis 2005: 17) smatraju da su razlozi za širu upotrebu PPP pristupa opravdani. Kao jedan od njih navode to što su nastavnici dobro upoznati sa načinom njegove primene, kao i to što se većina udžbenika stranih jezika bazira upravo na jezičkim aktivnostima koje su kreirane prema pomenutom pristupu podučavanja. Shodno tome, smatraju da organizacija nastavnog plana zasnovanog na TBL pristupu ima i svojih nedostataka. Učenici mogu da završe komunikaciju koristeći netačne jezičke strukture. Da bi se ovo izbeglo, nastavnicima se savetuje da uvedu aktivnosti zasnovane na proučavanju jezičkih formi kako bi se učenicima skrenula pažnja na gramatičke strukture u cilju povećanja preciznosti u izražavanju. Tornberi (Thornbury 1999: 98) upotpunjuje prethodno izneseno gledište i navodi još jednu manjkavost pomenutog pristupa. U pitanju je teškoća prilikom utvrđivanja jasnog kriterijuma za izbor zadataka, njihove evaluacije i ocenjivanja rezultata. Ovo je jedan od razloga što TBL nije široko rasprostranjen pristup, tako da veliki broj nastavnika kombinuje TBL i PPP model kako bi postigli željene rezultate.

\section{METODOLOGIJA}

\subsection{Teorijsko objašnjenje TBL strukture zadatka}

U ovom radu korišćen je eksperimentalni metod koji pripada grupi empirijskih istraživačkih metoda. Empirijski metodi se u nastavi učenja stranih jezika primenjuju na segment nastavnog procesa koji je potrebno istražiti radi dobijanja rezultata proizašlih iz konkretnih uslova nastave. Na taj način se utvrđuje efikasnost učinka nekih promena koje nastavnik svesno unosi u odgovarajući segment nastavnog procesa (Vučina 2009: 66, 76).

4 Dalje u radu biće korišćen akronim PPP (Presentation, Practice, Production) da označi pristup „obrade, vežbanja i utvrđivanja“. 
Razlog zbog koga su u jedan segment nastavnog plana iz predmeta Engleski jezik 2 kod studenata prve godne VŠTSS u Čačku uvedeni jezički zadaci bazirani na TBL pristupu bio je taj što je celokupan nastavni proces zasnovan na PPP pristupu. Prevashodni cilj uvođenja novog pristupa bio je da se proveri da li će i u kojoj meri studenti biti motivisaniji i spremniji da učestvuju u aktivnostima koje predstavljaju novinu u odnosu na već uhodani i uobičajeni način podučavanja i da se dobiju odgovori na istraživačka pitanja postavljena $u$ uvodnom delu rada.

Sledi teorijsko objašnjenje TBL strukture zadatka na osnovu koga je kreiran i primenjen konkretan ciklus sa studentima VŠTSS. TBL čini struktura koja uključuje ,predzadatak, ciklus zadataka (zadatak, planiranje i izveštaj) i usredsređenost na jezik (analiza i vežba)" (Edwards \& Willis 2005: 26). Predzadatak uvodi temu i uputstva za izradu predstojećeg zadatka. Zadatak predstavlja srž TBL pristupa jer učenici tada koriste ,proizvoljni” jezik da bi postigli cilj zadatka, a njihovo sopstveno učestvovanje smatra se najvećom motivacijom. Tokom izrade zadatka proces usvajanja jezika je najaktivniji jer su tada učenici podstaknuti da upotrebljavaju jezik na način koji njima odgovara da bi postigli svoj cilj (Edwards \& Willis 2005: 26, 27). Iz ovoga proizilazi da bi jezički zadaci u kojima se zahteva da učenici razgovaraju telefonom ili daju određena uputstva jedni drugima, rešavaju neki problem ili razmenjuju mišljenje o određenoj temi čine smisaonu jezičku aktivnost jer simuliraju situacije iz realnog života. Planiranje služi kao priprema za izveštavanje cele grupe učenika. U toku ove faze učenici u parovima ili u manjim grupama zapravo uvežbavaju ono što će reći pred svima u toku faze izveštaja. Konačnu fazu TBL strukture čini usredsređenost na jezik sa analizom i vežbanjem. U toku ove faze učenicima se skreće pažnja na korisne reči ili fraze, gramatiku ili neke druge karakteristike jezika u zavisnosti od zadatka. Nakon ovoga sledi vežbanje koje obuhvata aktivnosti neophodne radi sticanja sigurnosti prilikom upotrebe jezičkih elemenata koji se pojavljuju u fazi analize (Edwards \& Willis 2005: 27).

\subsection{Primena ciklusa zadataka u VŠTSS u Čačku}

U narednim odeljcima detaljno će biti opisane aktivnosti studenata koji su sledili TBL pristup, a koji je obuhvatio sve faze objašnjene u prethodnom pasusu. Cilj uvođenja ciklusa zadataka bio je da se pruži mogućnost studentima da govore i da vežbaju vokabular u vezi sa osećanjima i stavovima prema razlikama između polova i o njihovom međusobnom razumevanju. Istraživanje je izvršeno školske 2012/2013. godine. Ceo ciklus trajao je tri školska časa. Učesnici ispitivanja predstavljali su jednu grupu sačinjenu od šesnaest studenata prve 
godine studija VŠTSS koji su tada pohađali nastavu iz predmeta Engleski jezik 2. Studenti su bili na približno istom srednjem nivou jezičke komptencije engleskog jezika određenog na osnovu rezultata postignutih na ulaznom testu Zajedničkog evropskog referentnog okvira za žive jezike kojim se ocenjuje nivo postignuća stranog jezika.

Nastava iz predmeta Engleski jezik 2 odvija se dva puta sedmično po jedan čas predavanja i jedan čas vežbi. Cilj predmeta je unapređenje stečenih integrisanih jezičkih veština (čitanja, pisanja, slušanja i usmene komunikacije) kroz nadogradnju jezičkih sistema (leksičkih, fonetičkih, sintaksičkih i gramatičkih struktura) koji su obrađivani iz predmeta Engleski jezik 1, kao i razvijanje analitičkih sposobnosti konstruktivnog i kritičkog mišljenja, rešavanja problema kroz diskusije, upoređivanje, evaluaciju, izvođenje zaključaka, dijalog, interpersonalnu komunikaciju, građenje samopouzdanja i tolerancije u vezi sa određenom temom. Cilj nastavne jednice koja je bila predviđena za obradu i vežbanja u toku tri časa bio je usvajanje vokabulara koji je potreban da bi se objasnile razlike između polova i svakodnevnih problema u komunikaciji do kojih te razlike mogu da dovedu. Pomenuta tema bila je podstaknuta lekcijom "Why men don't iron?" iz skripte Engleski jezik 2 koja se koristi u nastavi u okviru istoimenog predmeta i koja je do tada obrađivana primenom PPP pristupa. Međutim, materijal koji je korišćen u okviru ovog istraživanja predstavljao je materijal koji se bavi zadatom temom, a koji su studenti samostalno pronašli i doneli na čas predviđen za obradu teme ${ }^{5}$.

Prvi čas obuhvatio je predzadatak i pripremu za izradu samog zadatka. U okviru ovog dela ciklusa uvedena je tema "The differences between men and women". Uvod u temu i zadatak podrazumevao je prezentovanje liste vokabulara, uglavnom prideva za opisivanje karaktera ljudi, zatim sortiranje reči i izraza u kategorije male/female i razgovor o razlici između polova. Ovaj čas bio je organizovan sa ciljem da se studenti upoznaju sa temom zadatka. Na tabli je ispisan vokabular koji bi mogao da opiše sličnosti i razlike između polova:

domesticated, emotional, communicative, talkative, better spatial abilities, fluent in speech, physical jobs

Provereno je razumevanje značenja datih reči i izraza, međutim, studenti nisu bili upoznati sa značenjem reči. 'domesticated' 'spatial abilities' and 'talkative', pa je značenje objašnjeno upotrebom poznatih sinonima. Studenti su

5 Materijal korišćen u nastavi nađen je na veb adresi www.oregoncounseling.org, pristupljeno 2. 5. 2013 . 
nastavili sa sortiranjem reči u kategorije male/female. Ovo su radili u parovima i podela je uglavnom izgledala ovako:

Male: better spatial abilities, physical jobs,

Female: domesticated, emotional, fluent in speech, talkative

Both genders: communicative

Takođe su dodali samostalno i neke svoje primere:

Female: spenders, more detailed.

Male: physically stronger, better drivers.

Studenti su bili podeljeni u četiri jednake grupe prema mestu sedenja radi obavljanja zadataka, tj. diskusije. Zadat je prvi deo ciklusa zadatka - da pronađu i sakupe bilo kakve izvore, tekstove, novinske članke koji se tiču prethodno pomenute teme i da pronđu pet razlika između polova i objašnjenja o uzrocima mogućih problema u komunikaciji zbog razlike u polovima u okviru svojih grupa.

Sam zadatak sastojao se od sakupljanja materijala na temu "The differences between men and women and the causes of these differences", diskusije o onome što su pronašli u okviru svojih grupa i donošenja odluke o tome šta žele da kažu pred ostalim grupama. Odabrana je diskusija kao zadatak jer se smatralo da je odgovarajuća nastavna aktivnost za ovakvu temu i da će studenti biti motivisani za razgovor. Diskusija je ,najprirodniji i najefikasniji način da se govor slobodno vežba" (Ur 2007: 2). To je prilika da učenici vežbaju jezik da bi razmenili i usaglasili mišljenja ili da bi rešili neki problem (Ur 2007: 2). Takođe, ovaj zadatak je odabran jer predstavlja kombinaciju zadataka koji se bave rešavanjem problema i pronalaženjem informacije koja nedostaje (Edwards \& Willis 2005: 19). Elementi rešavanja problema nalaze se u pitanju kojim se traži rešenje za posledice međusobnog nerazumevanja između polova. Elementi zadatka koji se bazira na pronalaženju informacije koja nedostaje sadržani su u činjenici da je svaka od četiri grupe pronašla različite odgovore za postavljeno pitanje iz materijala koje su sami pronašli, uglavnom preko interneta.

$\mathrm{Na}$ drugom času, nakon što su studenti sakupili materijal za diskusiju, usledilo je planiranje koje je obuhvatilo razmenu mišljenja i diskusiju u vezi sa informacijama između članova svake od grupa i zapisivanje razlika koje su želeli da predstave ostalim grupama. Kada su bili spremni, započeta je faza izveštavanja u okviru svih grupa zajedno. Praćen je rad grupa, a studenti su vodili diskusiju uz manje intervencije nastavnika. Usledila je diskusija na nivou cele grupe. $\mathrm{Na}$ tabli su zapisane reči i fraze oko kojih su se studenti složili nakon diskusije. Faza izveštaja u pisanom obliku izgledala je ovako:

male

better spatial abilities female

more emotional 
better sense for directions

more aggressive

more competitive

don't talk about problems more romantic

domesticated

spenders

discuss their problems

can do more things simultaneously

talkative

Deo strukture zadatka koji sadrži usredsređenost na jezik podrazumeva analizu jezika i vežbanje. Kako smatra Tornberi (Thornbury 1999: 134), jedan od nedostataka TBL pristupa jeste što je to „pristup usredsređen na značenje”, tako da se često dešava da „određeni oblici jezika” ostanu gotovo neprimećeni kod učenika, što vodi do netačne govorne preformanse. Zbog toga je za ovu fazu izabrano građenje prideva i definisanje razlika između prideva i priloga u građenju i upotrebi. Kao deo analize po dve grupe studenta razmenile su međusobno tekstove koje su pronašli, a zatim zapisali sve prideve i priloge koje su samostalno uočili u okviru datih tekstova. Nastavnik je smatrao da je najprimerenije bilo analizirati razliku između prideva i priloga jer su tekstovi koje su studenti odabrali sadržali upravo ove vrste reči: physically, easily, frequently, effectively, differently, primarily and decidedly. Definisana je, takođe, razlika između prideva koji su formirani od sadašnjeg i prošlog participa i onih koji koriste prefikse i sufikse za građenje, kao npr. interdependent or emotional. Konačno, studenti su u okviru gramatičkih vežbi koje su povezane sa prethodno pomenutim vrstama reči imali priliku da upotrebe stečeno znanje, a zatim su izdvojeni i napisani najčešći nastavci za formiranje prideva.

Vežba, kao poslednji deo faze usredsređenosti na jezik, urađena je kroz aktivnosti upotrebe jezika na trećem času. Prva aktivnost u okviru ove faze predstavljala je kombinaciju govora i pisanja i studenti su radili u parovima. Svako od njih trebalo je da intervjuiše po tri osobe po slobodnom izboru. $\mathrm{Na}$ osnovu sagovornikovih odgovora svaki student napravio je tabelu od tri kolone za svaku intervjuisanu osobu u koju je upisao osobu sa kojom intervjuisani ima problem, konkretan problem u komunikaciji koji se pojavljuje kod svakog od njih, kao i predloženo rešenje za pomenuti problem. Ovi problemi bili su opšte prirode, svedeni na svakodnevnu komunikaciju. Druga aktivnost urađena je kao razmena mišljenja, gde je trebalo da studenti predstave svoje rezultate usmeno. Primeri aktivnosti faze vežbanja nalaze se u narednom odeljku. Zatim je glasano za najčešći problem na nivou cele grupe i ispostavilo se da je to bio „kućni posao"".

6 Deo poglavlja br. 3 preuzet iz rada istoimenog autora ovog rada: Petrović 2013: 577-582. 


\section{REZULTATI I ANALIZA PODATAKA}

Ocena govorne sposobnosti izvršena je na osnovu dijagnostičkih listi za procenu uspešnosti izrade zadatka koje obuhvataju pregled odgovora dobijenih na osnovu intervjua. Dijagnostičke liste za procenu koriste se da bi prikazale „detaljne liste karakteristika koje se mogu upotrebiti za opisivanje uspešnosti izvođenja zadataka" (Luoma 2004: 78). Dijagnostčka lista urađena je u obliku DA/NE liste za svakog studenta, kako bi se lako moglo uočiti koje karakteristike je student umeo da iskaže, a koje nije. Na osnovu sadržaja i strukture dijagnostičkih listi izvršeno je ispitivanje da bi se moglo utvrditi:

a) da li su studenti naučili da upotrebe jezik kako bi mogli da objasne razlike između polova i moguće uzroke razlika?

b) da li su studenti umeli da identifikuju probleme u svakodnevnoj komunikaciji koji mogu biti prouzrokovani razlikama između polova i da li su na osnovu toga umeli da predlože sopstveno viđenje načina rešavanja datih problema?

$\mathrm{Na}$ osnovu međusobnih intervjua $\mathrm{u}$ parovima studenti su zapisivali dobijene odgovore, a zatim ih i usmeno prezentovali pred celom grupom. Tačnost izgovora i pisanja novih reči i izraza koje su koristili prilikom intervjua, a sa kojima se nisu susretali u prethodnim lekcijama, računati su za svakog studenta. Ovi rezultati izračunati su na bazi analize sadržaja koja je tipična za kvantitativna istraživanja gde istraživači definišu određene kategorije, a zatim računaju ukupan broj primera koji pripadaju svakoj pojedinačnoj kategoriji (Brown and Rodgers 2002: 34, 219).

Predstavljene su, takođe, i opservacije nastavnika kao metod prikupljanja podataka tipičan za kvalitativna istraživanja (Silverman 2006: 23, 24). Ovi načini prikupljanja i analize podataka odabrani su da bismo proverili da li se govorna kompetencija studenata poboljšala i da li je izrada komunikativnih zadataka na času i van časova povećala motivaciju i interesovanje studenata, budući da je ovaj pristup podučavanju prvi put primenjen u radu sa studentima.

Sledi postupak i način sprovedene analize podataka koja se zasniva na prethodno izloženim razmatranjima. Rezultati pregleda odgovora zasnovanog na obradi intervjua prezentovani su u tabelama na primeru jednog studenta. Prva tabela predstavlja primer za studenta koji je zabležio dobijene odgovore nakon obavljenog usmenog intervjua. Glavni cilj primenjenog pristupa podučavanju bio je da osposobi studente da govore o razlikama između polova, izraze moguće probleme koji nastaju prilikom komunikacije između osoba suprotnog pola i da predlože rešenja za navedene probleme.

Marija : 


\begin{tabular}{|l|l|l|l|}
\hline & $\begin{array}{c}\text { Person with whom } \\
\text { they have problems }\end{array}$ & \multicolumn{1}{|c|}{ Problem } & \multicolumn{1}{|c|}{ Solution } \\
\hline Verica & brother & $\begin{array}{l}\text { Irresponsible } \\
\text { housework }\end{array}$ & talking \\
\hline Teacher & brother and husband & housework & she does everything on her own \\
\hline Bratislav & sister & spender & talking with \\
\hline
\end{tabular}

Tabela 1. Primer odgovora dobijenih na osnovu intervjua u parovima za jednog studenta

Sledi primer dela usmenog izlaganja na bazi odgovora zapisanih u prvoj tabeli za jednog studenta nakon urađenog intervjua:

1. Marija: Verica has a problem with her brother because he's irresponsible and he doesn't do the housework.

2. T: And how do they solve it?

3. Marija: They talk usually.

Druga tabela urađena je u obliku DA/NE šeme dijagnostičke liste koja sadrži / ne sadrži vokabular koji je trebalo steći i upotrebiti. Nove reči i fraze koje je trebalo naučiti bile su određene na osnovu materijala koji su studenti sami pronašli i na bazi kojeg je diskusija sprovedena, a koje im nisu bile poznate iz prethodno obrađenih tekstova. Usmeno izlaganje na osnovu odgovora zapisanih u Tabeli 1. obrađeno je u Tabeli 2. kada je računata kompetentnost studenta da govori o odgovarajućoj temi.

Marija:

\begin{tabular}{|l|c|c|}
\hline & Yes & No \\
\hline $\begin{array}{l}\text { Can name the differences between genders and explain possible causes } \\
\text { of them }\end{array}$ & + & \\
\hline Identify possible problems in communication between genders & + & \\
\hline Suggest solutions for these problems & + & \\
\hline
\end{tabular}

Tabela 2. Primer dijagnostičke liste za jednog studenta urađen na osnovu usmene interpretacije Tabele 1.

Usmena prezentacija i pisanje reči iz kolona "problem" i "solution" analizirane su u trećoj tabeli da bi se utvrdio broj grešaka u izgovoru i pisanju prilikom upotrebe novih reči. 
Marija:

\begin{tabular}{|c|c|c|}
\hline Number of new words used & Pronunciation mistakes & Spelling mistakes \\
\hline 1 out of 4 & $/$ & $/$ \\
\hline
\end{tabular}

Tabela 3. Primer analize grešaka za jednog studenta

Ukupan broj reči korišćenih za opisivanje kolona "problem" i "solution" računate su da bi se odredio procenat naučenih novih reči i njihova upotreba na nivou cele grupe. Reči koje su brojane uključuju imenice, glavne glagole, prideve i priloge.

Rezultati na nivou cele grupe su sledeći:

a) ukupan broj reči korišćenih da se objasne problemi u komunikaciji: 56;

b) ukupan broj novih reči korišćenih da se objasne problemi u komunikaciji: 21 ;

c) procenat korišćenja novih reči na nivou grupe: $37,5 \%$;

d) broj grešaka u izgovoru novih reči: 2 , što čini $9,5 \%$;

e) broj grešaka u pisanju novih reči: 6 , što čini $28,6 \%$.

Budući da je na času na kome je urađeno intervjuisanje bilo dvanaest od ukupno šesnaest studenata, rezultati su pokazali da je jedanaest od dvanaest studenata umelo da upotrebi reči i izraze da bi opisali razlike između polova i objasnili moguće uzroke za to, da identifikuju moguće probleme u komunikaciji i da predlože svoja rešenja. Jedan student umeo je da upotrebi reči i izraze da bi objasnio razlike između polova i da identifikuje moguće probleme, ali nije uspeo da predloži rešenje datih problema.

Sledi kratak opis zapažanja nastavnika u vezi sa motivacijom i saradnjom studenata u izradi zadataka. Studenti koji su sledili TBL pristup aktivno su sarađivali $\mathrm{u}$ ispunjavanju zahteva nastavnika. $U$ toku faze zadatka sve četiri grupe su učestvovale u sakupljanju materijala. $U$ toku faze planiranja veoma zainteresovano su razmenjivali materijale koje su sakupili. Članci koje su našli bili su prilično komplikovani za njihov nivo znanja, ali su studenti uspeli da odaberu reči i izraze koji su im bili potrebni za izlaganje pred celom grupom. Iako je inicijalna ideja bila da se odrede predstavnici za svaku grupu koji bi izneli usaglašene ideje ispred svake od četiri grupe u toku faze izveštaja, ispostavilo se da su ih dodatna pitanja navela na debatu u kojoj je većina njih učestvovala. Tako su imali priliku da koriste proizvoljno odabran jezik, međutim, nisu svi podjednako učestvovali. U toku faze usredsređenosti na jezik svi studenti dobili su priliku da iskažu sopstveno viđenje problema u komunikaciji. Upotreba jezika u ovoj fazi 
bila je predmet evaluacije koja je pokazala da su studenti dobro razumeli zahteve koje je trebalo ispuniti, ali su uglavnom koristili već poznate reči da bi izvršili zadatak. Gramatička tačnost upotrebljenog jezika nije bila predmet analize, ali su određene greške bile očigledne.Veći broj studenata je pogrešno upotrebio treće lice jednine prezenta i u potvrdnim i upitnim rečenicama. U okviru ove faze tri jezičke veštine su bile zastupljene: govor, pisanje i slušanje. Početni cilj da se motivišu studenti je prilično uspešno realizovan jer su oni veoma zainteresovano učestvovali u toku svih faza strukture zadatka i pokazalo se da su stekli očekivane kompetencije primernom ovog pristupa ${ }^{7}$.

\section{ZAKLJUČAK}

Ovaj rad nastao je sa namerom da približi ishode učenja stranih jezika primenom TBL pristupa koji još uvek nije prihvaćen u onoj meri u kojoj je to dobro razrađeni PPP pristup. Cilj sprovođenja ovog istraživanja bio je da pokaže da diskusija kao oblik zadatka omogućava studentima razmenu mišljenja na način na koji to čine u realnim situacijama, dajući im priliku da govore i slušaju jedni druge. Na osnovu izvedenih rezultata pokazalo se da su ovi studenti ipak pokazali malo veći napredak u pogledu preciznosti u izgovoru korišćenih novih reči u zadatom kontekstu u odnosu na preciznost u pisanju istih tih reči, što je i bilo očekivano s obzirom na to da je vežbanje usmene upotrebe reči bilo zastupljenije. Opažanja nastavnika u vezi sa istraživačkim pitanjem motivisanosti za rad pokazala su da se studenti uspešno snalaze u učenju i usvajanju jezika kada u njima aktivno učestvuju i da veliki doprinos daje njihova svest o tome da rade nešto što oni sami smatraju korisnim i nešto što nema isključivo jezičku svrhu.

Ovo istraživanje može se iskoristiti kao polazna osnova za sprovođenje longitudinalnog istraživanja baziranog na TBL pristupu podučavanju. Budući da su studenti bili motivisani za rad i spremni da prihvate nove izazove u pogledu teme i načina obrade, za nastavnika bi izazov predstavljao da celokupan nastavni plan prilagodi TBL pristupu, ili ga pak integriše u nastavni proces uporedo sa preovlađujućim pristupom podučavanja koji se koristi u nastavi, što bi moglo uključiti i obradu gramatike, čitanje i razumevanje tekstova. Ono što je takođe moguće proveriti kvantitativnim istraživanjima jeste upoređivanje napretka učenika primenom PPP i TBL pristupa prilikom obrade istog segmenta nastavnog plana.

7 Deo poglavlja preuzet iz rada istoimenog autora ovog rada: Petrović 2013: 586, 587. 


\section{LITERATURA:}

Brown, J. D., T. S. Rodgers (2002). Doing Second language research. Oxford: Oxford University Press.

Edwards, C., J. Willis. (2005). Teachers Exploring Tasks in English Language Teaching. Houndmills: Palgrave Macmillan.

Larsen-Freeman, D. (2000). Techniques and principles in language teaching. $2^{\text {nd }}$ ed. Oxford: Oxford University Press.

Lightbown, M. P., N. Spada. (2006). How languages are learned. Revised ed. Oxford: Oxford University Press.

Luoma, S. (2004). Assessing Speaking. Cambridge: Cambridge University Press.

Petrović, V. (2013) "The Values of the Task Based Learning (TBL) in Learning Vocabulary and Improving Speaking Competence" in Language, Literature, Values, ur. B. Mišić Ilić i V. Lopičić (Niš: Univerzitet u Nišu, Filozofski fakultet): 577-588.

Silverman, D. ( 2006). Interpreting Qualitative Data. Revised ed. Oxford: Alden Press.

Thornbury, S. (1999). How to Teach Grammar. Essex: Longman.

Ur, P. (1996). A Course in Language Teaching. Cambridge: Cambridge University Press.

Ur, P. (2007). Discussions that work. Revised ed. Cambridge: Cambridge University Press.

Vučina R. (2009). Metodologija istraživanja u metodici nastave stranih jezika. Beograd: Čigoja štampa.

Willis, J. (1996). A Framework for Task-Based Learning. Oxford: Oxford University Press. 


\author{
Vesna Petrović \\ University of Belgrade \\ Faculty of Philology - doctoral studies, module Culture \\ Belgrade \\ Technical College Čačak \\ Čačak \\ vesna.petrovic@vstss.com
}

\title{
APPLYING THE TASK-BASED LEARNING (TBL) APPROACH TO ACQUIRING \\ NEW VOCABUALRY OF ENGLISH AS A FOREIGN LANGUAGE AND \\ IMPROVING SPEAKING COMPETENCE WITH REGARD TO THE SPECIFIED TOPIC
}

\section{Summary}

This paper deals with analyzing and assessing the outcomes of the Task-based Learning (TBL) approach in acquiring and using new vocabulary of English as a foreign language with the students of Technical College in Čačak. The first part of the paper deals with the theoretical hypotheses and perspectives of the TBL and gives an explanation of the task cycle which is the core of this approach. The TBL fulfills all the necessary conditions for learning a foreign language: exposure to real spoken and written language in use, use of the language and motivation as well as the instruction in language, i.e. the focus on form. Also the TBL framework is presented in detail.The research questions that this paper tries to answer are whether the discussion, as the part of the communicative task in class, will enable the students to use new vocabulary appropriately in the context of the specified topic; whether the students will use new vocabulary more accurately concerning pronunciation and spelling if they have more opportunities to use vocabulary in realistic and meaningful ways, and whether their motivation and willingness to participate in performing the communicative activities within the task will be increased. To answer these questions the discussion as the task was introduced into learning process. The plan of the research was to analyse oral and written results of the class survey which was done in pairs in the form of the interview with the same topic as in the discussion. Also the correctness of the pronunciation and spelling of new words and phrases were counted for the analysis. These results were subjected to the content analysis that is typical of the quantitative research. Teacher's observations as data collection method typical for qualitative research were also presented.

Key words: task-based learning teaching (TBL), communicative approach, task, discussion, new vocabulary, assessing speaking.

Primljeno: 10. 5. 2016.

Prihvaćeno: 5. 5. 2016. 